\title{
Fuzzy Multiple Criteria Decision Making Method Applied to Evaluation of Service Quality for Five-Star Hotels
}

\author{
Yu-Lung Wu, Ju-Jun Ting \\ Department of Information Management, I-Shou University, Taiwan, China \\ E-mail: wuyulung@isu.edu.tw, bunes2001@yahoo.com.tw
}

\begin{abstract}
Fuzzy Multiple Criteria Decision Making (FMCDM) theory combined with the Expert Opinion method to provide appropriate evaluation criteria weights and fuzzy numbers, and uses Fuzzy Ranking methods for ranking based on an integrated assessment to serve as the basis and reference for the "Best Five-Star Tourist Hotel Service Quality Award" in Taiwan. This study is based on a sample rating of 8 participating hotels, supplemented by relevant literature for more in-depth discussions, and puts forward relevant practical and research proposals.
\end{abstract}

Keywords-component; Fuzzy Multiple Criteria Decision Marking; Evaluation of Service Quality; Five-Star Hotels

\section{INTRODUCTION}

With continuous strong growth in Taiwan's tourism industry, the increase in the number of world-class five-star hotels is an important international tourism quality index that cannot be ignored. Since 2009, the Tourism Bureau has been developing "Project Vanguard for Excellence in Tourism", which implements management criteria and evaluation mechanisms in accordance with international standards in order to improve the competitiveness of tourist accommodation, thus leading to the emergence of hotels that have been rated according to a star-based system [1].

The implementation of a hotel evaluation system can improve the overall service quality of the hotel industry in our country, assisting domestic and foreign consumers in selecting accommodation in accordance with their travel budget and needs. Compared with the development conditions of international five-star hotels, star hotel evaluation in Taiwan had a late start and has lost many market competitive advantages. In addition, there exists the need for a comprehensive review of the history of hotel evaluation mechanisms in Taiwan. Determined to become a major tourist destination in Asia in future, Taiwan must adopt a more expand field of view, and define the growth in quantity and quality of world-class five-star hotels as one of the key indicators to enhance the quality of Taiwan's international tourism.

This study is aimed to achieve fair evaluation of the service quality of five-star tourist hotels. We have therefore constructed an expert decision-making model which can provide the government and domestic five-star hotels with the best possible evaluation reference by using FMCDM. This study also explores the most objective way in which to select the five-star hotel with the best service quality, based on different and limited assessment factors, taking the "Fivestar Tourist Hotel Service Quality Award of Taiwan" as an example.

\section{THE RESEARCH FRAMEWORK OF FUZZY DECISION- MAKING MODEL}

Fuzzy theory is commonly used to express uncertain and fuzzy data. Its major contribution is to express qualitative and quantitative data in real life in the form of mathematical structures [2], in order to provide a judgment rule more in line with the real life, so that decision makers can clearly define problems and compare data. Today's society is becoming increasingly complex, and most decisions have fuzziness and uncertainty. Therefore, it is not feasible to rely on a single criterion for judgment. On the contrary, there is the need to consider a number of criteria characteristics, and in order to have an objective and fair decision-making process, the evaluation must rely more on FMCDM to achieve a good conclusion [3].

In recent years, FMCDM has been successfully applied in many practical fields, for examples: suppliers evaluation [4, 5, 6], risk assessment [7], financial or accounting evaluation [8, 9] etc. However, the application on five-star hotel service quality evaluation has not yet been found in relevant literature. Therefore, this study provides a fair, simple evaluation method mainly by using FMCDM.

The research framework of evaluation model in this study is shown in Fig. 1.

\section{SAMPLE DESIGN}

In this study a variety of relevant literature was collected to identify various impact factors to form the initial evaluation criteria. FMCDM was used to extract knowledge and experience of experts in relevant fields, and to select the most important evaluation criteria. After that, the system carried out fuzzy operation processes, and obtained a comprehensive evaluation of various programs by integration. Next, the best result was achieved as a more objective decision through "Max Min Set" Fuzzy Ranking Method [10]. The above data were quantified and weighted to establish the evaluation model in this study. The eight evaluation items in stage 2 of the "Five-Star Hotel Service Quality Evaluation" evaluation of "service quality" (switchboard services, booking services and counter services, network services, traffic and parking, housekeeping quality, restaurant services and dining quality, fitness facilities services, employee training effectiveness) were assessed by 
six domestic experts from various fields such as industry, government, academia, research, and international hotels and tourism, who served as the decision makers. Eight famous hotels in Taiwan shortlisted for international five-star hotel status were selected as examples for verification purposes in this study.

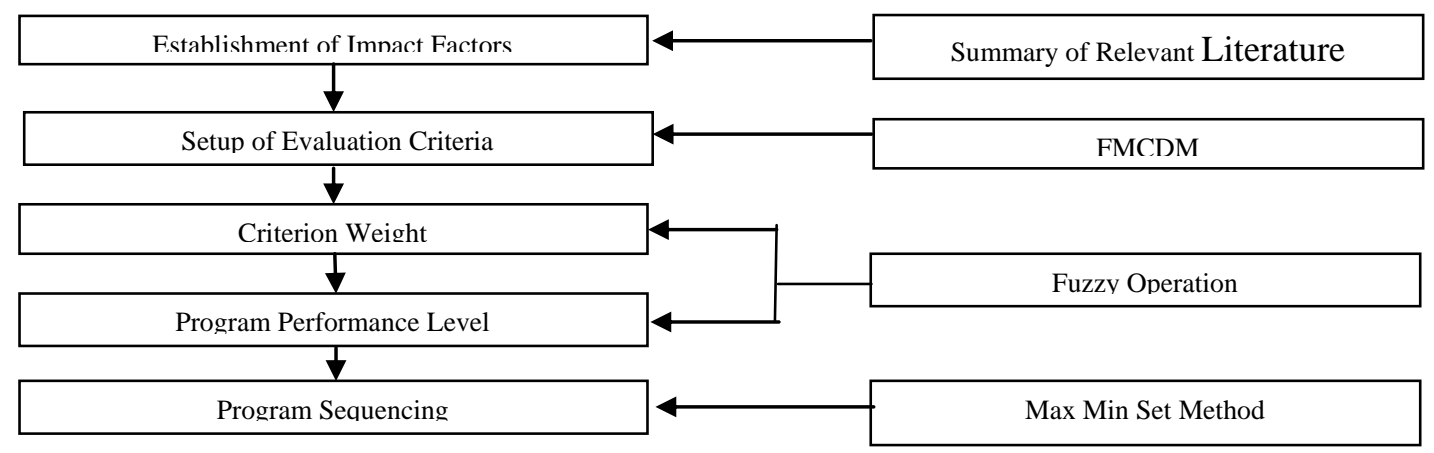

Figure 1 Research Framework of Evaluation Model

\section{EMPIRICAL CALCULATIONS}

The weight of each evaluation criterion was determined according to the respective opinions of the six decisionmaking experts, and the evaluation was made by language variables, and then converted to semantic variable fuzzy numbers. The evaluations of six decision-making experts on various criteria weights were integrated and each criteria weight was calculated using a formula, as shown in Table 1 .
Decision-making experts determined the value of evaluation criteria of the "participating hotels". The criteria ratings of six decision-making experts on "eight participating hotels" were integrated and the criteria rating of each participating hotel was calculated and integrated using a formula. Then, the criteria rating of each participating hotel was formalized, results were calculated using a formula. The overall rating results of each participating hotel's criteria were calculated using a formula, as shown in Table 2

TABLE I. SEMANTIC EVALUATIONS AND CRITERIA WEIGHT OF SIX DECISION MAKERS

\begin{tabular}{|c|c|c|c|c|c|c|c|}
\hline evaluation criterion & A1 & A2 & A3 & A4 & A5 & A6 & $\begin{array}{c}\text { criteria weight fuzzy } \\
\text { numbers }\end{array}$ \\
\hline P1 & H & VH & H & VH & VH & H & $(0.725,0.9,0.975)$ \\
\hline P2 & VH & MH & VH & H & MH & VH & $(0.675,0.85,0.925)$ \\
\hline P3 & MH & H & M & H & H & M & $(0.525,0.675,0.825)$ \\
\hline P4 & ML & L & MH & VH & L & MH & $(0.35,0.508,0.633)$ \\
\hline P5 & H & M & H & MH & M & H & $(0.525,0.675,0.825)$ \\
\hline P6 & H & H & VH & MH & MH & VH & $(0.65,0.817,0.917)$ \\
\hline P7 & M & H & M & H & MH & M & $(0.475,0.625,0.775)$ \\
\hline P8 & H & MH & VH & HV & M & VH & $(0.575,0.80,0.912)$ \\
\hline
\end{tabular}

TABLE II. OVERALL RATING OF EACH PARTICIPATING HOTEL'S CRITERIA

\begin{tabular}{|c|c|c|c|c|c|c|c|c|c|c|c|c|c|c|c|c|c|c|c|c|c|c|c|c|}
\hline 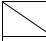 & \multicolumn{3}{|c|}{$\mathrm{P} 1$} & \multicolumn{3}{|c|}{$\mathrm{P} 2$} & \multicolumn{3}{|c|}{ P3 } & \multicolumn{3}{|c|}{ P4 } & \multicolumn{3}{|c|}{ P5 } & \multicolumn{3}{|c|}{ P6 } & \multicolumn{3}{|c|}{ P7 } & \multicolumn{3}{|c|}{ P8 } \\
\hline W1 & 0.311 & 0.530 & 0.731 & 0.238 & 0.450 & 0.653 & 0.329 & 0.540 & 0.773 & 0.170 & 0.344 & 0.525 & 0.315 & 0.511 & 0.753 & 0.243 & 0.459 & 0.687 & 0.230 & 0.403 & 0.625 & 0.213 & 0.405 & 0.608 \\
\hline W2 & 0.214 & 0.410 & 0.601 & 0.218 & 0.425 & 0.626 & 0.301 & 0.497 & 0.743 & 0.159 & 0.329 & 0.505 & 0.274 & 0.458 & 0.689 & 0.406 & 0.663 & 0.916 & 0.230 & 0.409 & 0.611 & 0.195 & 0.382 & 0.583 \\
\hline W3 & 0.388 & 0.627 & 0.836 & 0.437 & 0.700 & 0.925 & 0.358 & 0.583 & 0.803 & 0.191 & 0.370 & 0.576 & 0.356 & 0.569 & 0.803 & 0.304 & 0.535 & 0.773 & 0.306 & 0.510 & 0.736 & 0.391 & 0.630 & 0.861 \\
\hline W4 & 0.505 & 0.779 & 0.975 & 0.437 & 0.700 & 0.925 & 0.344 & 0.552 & 0.810 & 0.233 & 0.442 & 0.627 & 0.370 & 0.587 & 0.825 & 0.426 & 0.689 & 0.945 & 0.332 & 0.543 & 0.778 & 0.391 & 0.630 & 0.861 \\
\hline W5 & 0.272 & 0.482 & 0.679 & 0.298 & 0.525 & 0.735 & 0.372 & 0.601 & 0.825 & 0.202 & 0.390 & 0.582 & 0.329 & 0.534 & 0.760 & 0.345 & 0.586 & 0.830 & 0.230 & 0.403 & 0.625 & 0.266 & 0.472 & 0.684 \\
\hline W6 & 0.369 & 0.603 & 0.810 & 0.258 & 0.475 & 0.680 & 0.301 & 0.503 & 0.728 & 0.159 & 0.323 & 0.518 & 0.315 & 0.517 & 0.739 & 0.223 & 0.433 & 0.658 & 0.243 & 0.420 & 0.646 & 0.231 & 0.427 & 0.633 \\
\hline W7 & 0.485 & 0.747 & 0.966 & 0.397 & 0.650 & 0.871 & 0.344 & 0.552 & 0.810 & 0.244 & 0.462 & 0.633 & 0.356 & 0.563 & 0.818 & 0.467 & 0.740 & 1.002 & 0.332 & 0.543 & 0.778 & 0.355 & 0.585 & 0.811 \\
\hline W8 & 0.447 & 0.707 & 0.897 & 0.437 & 0.700 & 0.925 & 0.315 & 0.515 & 0.765 & 0.202 & 0.390 & 0.582 & 0.356 & 0.569 & 0.803 & 0.406 & 0.663 & 0.916 & 0.332 & 0.549 & 0.764 & 0.391 & 0.630 & 0.861 \\
\hline
\end{tabular}


The distance and closeness coefficients for each participating hotel with reference to the positive ideal solution and to the negative ideal solution were calculated, and were then sorted based on their values using the TOPSIS evaluation method. After the positive ideal solution and the negative ideal solution were calculated, the relative closeness coefficient of the participating hotels was obtained, and these were then sorted for an evaluation result, as shown in Table 3

TABLE III. EXPLICIT VALUES OF OVERALL RATING RESULTS

\begin{tabular}{|c|r|r|r|r|}
\hline Hotel & $d^{+}$ & $d^{-}$ & \multicolumn{1}{c|}{$C C$} & Order \\
\hline W1 & 4.876 & 3.495 & 0.417 & 8 \\
\hline W2 & 4.675 & 3.512 & 0.428 & 6 \\
\hline W3 & 4.195 & 4.227 & 0.501 & 4 \\
\hline W4 & 3.904 & 4.554 & 0.538 & 1 \\
\hline W5 & 4.597 & 3.764 & 0.450 & 5 \\
\hline W6 & 4.825 & 3.546 & 0.423 & 7 \\
\hline W7 & 3.961 & 4.493 & 0.531 & 2 \\
\hline W8 & 4.054 & 4.379 & 0.519 & 3 \\
\hline
\end{tabular}

As indicated in Table 3, the ranking results of eight participating hotels after evaluation were: W4> W7 $>$ W $8>$ W3 $>$ W5 $>$ W2 $>$ W6 $>$ W7. Therefore, the conclusion of this study is that $\mathrm{W} 4$ is the most preferred five-star tourist hotel.

\section{CONCLUSION}

This study taking the "Five-star Tourist Hotel Service Quality Award" as an example puts forward the characteristics of the FMCDM theory in order to improve the shortcomings of traditional decision-making evaluation. Through the operation processes of fuzzy sets, fuzzy numbers and defuzzification, the data were converted to useful information in order to achieve the most objective evaluation method. Therefore, the importance of evaluation criteria was assessed mainly by the decision makers, and the opinions of scholars and experts were integrated to select the criteria of higher importance as evaluation indices by using FMCDM. Thus, the complexity of consumer evaluation caused by too many evaluation factors is reduced, so that the consumers can quickly make the most objective choice. After evaluation by experts, it is concluded that W4 is the most preferred five-star hotel among the eight hotels evaluated.

\section{ACKNOWLEDGMENT}

The authors are grateful to Ministry of Science and Technology for financially supporting this research under MOST 104-2410-H-214-011.

\section{REFERENCES}

[1] Tourism Bureau, Ministry of Transportation and Communications. Information, 2016.[Online]. Available: http://admin.taiwan.net.tw/upload/public/20150408/246b271a-84034377-8686-dea99f2afdb1.pdf.

[2] L. A. Zadeh, Fuzzy set, "Information and Control", $3^{\text {rd }}$ ed., vol.8, 1965, pp. 338-353.

[3] J.F. Ding and G.S. Liang, "Using fuzzy MCDM to select partners of strategic alliances for liner shipping", Information Sciences, vol.173, pp.197-225,2005.

[4] T.C. Chu and R. Varma, "Evaluating suppliers via a multiple levels multiple criteria decision making method under fuzzy environment", Computers \& Industrial Engineering, vol.62, no.2, 653-660, 2012.

[5] K. Govindan, S. Rajendran, J. Sarkis and P. Murugesan, "Multi criteria decision making approaches for green supplier evaluation and selection: a literature review", Journal of Cleaner Production, Vol.98, pp.66-83,2015.

[6] D. Kannan, R. Khodaverdi, L. Olfat, "A. Jafaria and A. Diabat, Integrated fuzzy multi criteria decision making method and multiobjective programming approach for supplier selection and order allocation in a green supply chain", Journal of Cleaner Production, vol.47, pp.355-367, 2013.

[7] Y.C. Kuo and S.T. Lu, "Using fuzzy multiple criteria decision making approach to enhance risk assessment for metropolitan construction projects", International Journal of Project Management, vol.31, no. 4, pp. 602-614, 2013.

[8] V. Keršulienė and Z. Turskis, "An Integrated Multi-criteria Group Decision Making Process: Selection of the Chief Accountant", Procedia - Social and Behavioral Sciences, vol.110, pp. 897-904, 2014.

[9] K. Yalcin, "A. Bayrakdaroglu and C. Kahraman, Application of fuzzy multi-criteria decision making methods for financial performance evaluation of Turkish manufacturing industries", Expert Systems with Applications, vol.39, no.1, pp.350-364, 2012.

[10] C.T. Chen, "Extensions of the TOPSIS for Group Decision-Making under Fuzzy Environment", Fuzzy Sets and Systems, vol.114, pp. 1-9, 2000. 